\title{
Comparison of the success rate of inguinal approach with classical pubic approach for obturator nerve block in patients undergoing TURB
}

\author{
Youn Yi Jo' ${ }^{1}$, Eunkyeong $\mathrm{Choi}^{2}$, and Hae Keum Kil ${ }^{2,3}$ \\ ${ }^{1}$ Department of Anesthesiology and Pain Medicine, Gachon University of Medicine and Science Gil Medical Center, Incheon, \\ ${ }^{2}$ Department of Anesthesiology and Pain Medicine, ${ }^{3}$ Anesthesia and Pain Research Institute, Yonsei University College of Medicine, \\ Seoul, Korea
}

Background: During transurethral resection of bladder tumors (TURB) under spinal anesthesia, electrical resection of the lateral wall mass may cause violent adductor contraction and possible inadvertent bladder perforation. Therefore, obturator nerve block (ONB) is mandatory after spinal anesthesia to avoid adductor muscle contraction. We compared the success rate and efficacy of an inguinal approach, to a pubic approach for ONB.

Methods: One hundred and two patients who required ONB undergoing TURB with spinal anesthesia were included in this study. After spinal anesthesia, ONB was performed with an inguinal approach (Group I, $\mathrm{n}=51$ ) or pubic approach (Group P, $\mathrm{n}=51$ ) using a nerve stimulator. In the pubic approach, a needle was inserted at a point $1.5 \mathrm{~cm}$ lateral and $1.5 \mathrm{~cm}$ inferior to the pubic tubercle. For the inguinal approach, a needle was inserted at the midpoint of the femoral artery and the inner margin of the adductor longus muscle $0.5 \mathrm{~cm}$ below the inguinal crease. If the adductor contracture had not occurred by the 3rd attempt, it was defined as a failed block. Puncture frequency, success rate, anatomical characteristics, and the presence of adductor muscle contraction during operation were evaluated.

Results: The success rate of ONB was higher in group I compared to group P (96.1\% vs. 84.0\%, P = 0.046) and the frequency of needle attempts was lower in group I than in group $\mathrm{P}(1.8 \pm 0.9$ vs. $1.3 \pm 0.6, \mathrm{P}=0.01)$.

Conclusions: The inguinal approach for ONB appears to be technically easier and offers certain anatomical advantages when compared to the pubic approach. (Korean J Anesthesiol 2011; 61: 143-147)

Key Words: Inguinal approach, Obturator nerve block, TURB.

Received: December 14, 2010. Revised: 1st, January 10, 2011; 2nd, January 17, 2011. Accepted: January 19, 2011.

Corresponding author: Hae Keum Kil, M.D., Department of Anesthesiology and Pain Medicine, Anesthesia and Pain Research Institute, Yonsei University College of Medicine, 250, Seongsan-no, Seodaemun-gu, Seoul 120-752, Korea. Tel: 82-2-2228-2414, Fax: 82-2-2228-7897, E-mail: hkkil@yuhs.ac

(c) This is an open-access article distributed under the terms of the Creative Commons Attribution Non-Commercial License (http:// creativecommons.org/licenses/by-nc/3.0/), which permits unrestricted non-commercial use, distribution, and reproduction in any medium, provided the original work is properly cited. 


\section{Introduction}

Obturator nerve block (ONB) has been commonly used to treat hip joint pain and relieve adductor muscle spasms associated with central neurologic problems. ONB is also frequently used in urologic surgery to suppress the obturator reflex during transurethral resection of the lateral bladder wall. If resectors directly stimulate the obturator nerve as it passes in close proximity to the bladder wall, sudden, violent adductor muscle contraction can result. This is potentially dangerous, increasing the risk of serious complications such as bladder wall perforation, vessel laceration, incomplete tumor resection, and obturator hematomas [1,2]. General anesthesia, neuromuscular blocking drugs $[3,4]$ as well as subarachnoid and epidural anesthesia have not demonstrated to be beneficial for the prevention of this contraction of the adductor muscle. Selective ONB is considered as the safest and most effective method to resolve these problems. Because of a lack of clear anatomic landmarks, the block complexity, patients' discomforts and inconsistent results, the classical method (Labat's technique) remained forgotten until 1967, when this method was simplified [5]. Presently, this classical pubic approach is still commonly used for ONB using a nerve stimulator, although the success rate varies (60.5-91.7\%) [6,7]. In 1993, the interadductor approach was described, in which a needle is inserted behind the upper end of the adductor longus muscle [8]. Recently, a simple and reliable new method (the inguinal approach) was described by Choquet et al. [9], in which the needle is inserted at the mid-point of the femoral arterial pulse and the inner side of the adductor longus muscle on the inguinal crease.

This randomized clinical study was undertaken to compare the success rate of the inguinal and pubic approach in ONB with spinal anesthesia for transurethral resection of bladder lateral wall masses.

\section{Materials and Methods}

After approval from our institutional review board and the written informed consent from patients was obtained, 102 patients scheduled to transurethral resection of bladder lateral wall masses under spinal anesthesia who required ONB were included in this study. Patients with advanced cardiac and respiratory insufficiency, allergy to local anesthetics, preexisting neurologic deficits, prior operations involving the hip and the inguinal region and bleeding tendency were excluded. ONB was perforemed in the patients who were asked ONB by urologist because of invasive lateral bladder wall tumor. And these patients were randomly allocated to the conventional pubic approach group (Group $\mathrm{P}, \mathrm{n}=51$ ) or new inguinal approach group (Group I, $n=51$ ). On arrival to the operating room, standard anesthetic monitors were applied and $0.9 \%$ normal saline $300 \mathrm{ml}$ was given intravenously. A spinal block was performed with a 25 G Quincke needle at the L3-4 or L4-5 interspace in a lateral decubitus position. After confirming freeflow and clear CSF, $0.5 \%$ hyperbaric bupivacaine ( $8 \mathrm{mg}$ ) was administered. In a supine position, sympathetic and sensory blocks were checked with an alcohol swab and pin-prick test. When the sensory level block reached above T12, ONB was performed according to group assignment. All ONB were performed by 2 investigators that alternated procedures and they were not involved in further treatment of those patients. ONB was performed with a $10 \mathrm{~cm}$ Teflon-insulated needle (21G Stimuplex ${ }^{\circledR}$ A, B. Braun Melsungen AG, Germany) using a nerve stimulator (B. Braun Melsungen. AG, Germany). Nerve stimulation was applied using a current of $0.5 \mathrm{~mA}$ at $1 \mathrm{~Hz}$ only.

\section{Obturator nerve block}

Pubic approach (Fig. 1): The patient was placed in a supine position with the legs slightly abducted and externally rotated. After identification of the pubic tubercle, a needle was inserted perpendicularly to the skin $1.5 \mathrm{~cm}$ lateral and $1.5 \mathrm{~cm}$ inferior to the tubercle. When the needle made contact with the inferior border of the superior pubic ramus, the needle was withdrawn short of the tip and then slipped along the anterior pubic wall. After this, the needle was redirected anteriorly/posteriorly and slightly withdrawn again and advanced cephalically and laterally at an angle of $45^{\circ}$ until contraction of the thigh

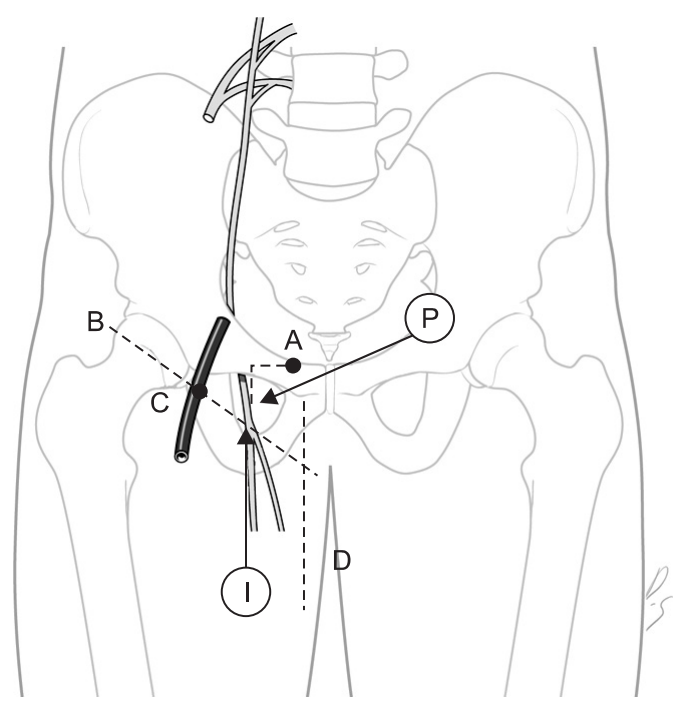

Fig. 1. The obturator nerve block. A: pubic tubercle, B: inguinal crease, C: femoral artery, D: inner border of the adductor longus tendon, P: needle insertion point for the conventional pubic approach, I: needle insertion point for the modified inguinal approach. 
adductor muscles were observed. When the adductor muscle was contracted, $10 \mathrm{ml}$ of $1 \%$ lidocaine was administered after confirmation so that no blood was present after negative aspiration. If there were no responses of adductor muscles after the third attempt, $15 \mathrm{ml}$ of lidocaine was instilled evenly and the needle was withdrawn: this was defined as a failed ONB.

Inguinal approach (Fig. 1): The patient was placed in a supine position with the legs slightly abducted and a line marked the inguinal crease. After identification of the adductor longus tendon in the medial part of the thigh, a mark on the skin was made in the inguinal crease at the midpoint of the line drawn between the femoral arterial pulse and the inner border of the adductor longus tendon. This approach was performed in 2 stages. First, the needle was inserted $0.5 \mathrm{~cm}$ below the mark in the cephalad direction with a $30^{\circ}$ angle to the skin until adductor muscle (adductor longus or gracilis) contractions were elicited. After identification of the contractions (anterior side of the inner thigh and the medial part of the knee), $5 \mathrm{ml}$ of a $1 \%$ lidocaine dose was administered (anterior branch block). Then the needle was advanced deeper about $0.5-1 \mathrm{~cm}$ and $5^{\circ}$ laterally. When the contraction of the adductor magnus muscle occurred (i.e. noticeable hip adduction), $5 \mathrm{ml}$ of $1 \%$ lidocaine was injected (posterior branch block). If there were no contractions of the adductor muscles after the third attempt, $15 \mathrm{ml}$ of lidocaine was instilled evenly and this was defined as a failed ONB. Also, if the obturator sign occurs during the procedure, in cases with successful adductor contraction in the $\mathrm{ONB}$, that case was defined as a failed case.

The number of needle attempts and the needle depth were recorded. An independent observer who was blinded to the approach evaluated the obturator signs during operation. We planned to administer a general anesthesia with laryngeal mask airway (LMA) when the obturator sign occured during operation.

Statistical analyses were performed using PASW Statistics $18^{\circledR}$ (SPSS Inc, Chicago, IL, USA). Sample size was calculated based on our preliminary study. For an $\alpha$ level of 0.05 and a

Table 1. Patient Characteristics and Data from Spinal Anesthesia

\begin{tabular}{lcc}
\hline \multicolumn{1}{c}{ Group } & Group P (n=50) & Group I (n=51) \\
\hline Age (yrs) & $64.5 \pm 10.2$ & $62.4 \pm 11.8$ \\
Sex (M/F) & $42 / 8$ & $44 / 7$ \\
Weight (kg) & $64.3 \pm 12.3$ & $66.5 \pm 10.9$ \\
Height (cm) & $164.2 \pm 7.3$ & $166.5 \pm 7.5$ \\
Maximal sensory block & & \\
$\quad$ Cold & T 10 (T5-L1) & T 10 (T5-L1) \\
$\quad$ Sensory & T 10 (T5-L1) & T 10 (T6-L1) \\
\hline
\end{tabular}

Data represent the mean $\pm S D$, median (range), or number of patients. Group P: conventional pubic approach (Labat's technique), Group I: inguinal approach. power of $80 \%, 49$ patients were required for each group to detect a minimum of a $30 \%$ difference in the success rate. To compensate for a $5 \%$ possible drop out, 51 patients were included in this study. Data are presented as mean \pm SD or number of patients. Patients' characteristics were compared using a student's t-test or Fisher's exact test where appropriate. Differences between the groups were analyzed using student's t-test, Mann-Whitney rank sum test, chi square test, and Fisher's exact test when appropriate. A value of $\mathrm{P}<0.05$ was considered statistically significant.

\section{Results}

One patient in the group $\mathrm{P}$ was excluded from the analysis of the study due to operative procedure changes. There were no significant differences in patient characteristics, local anesthetic dosage and sensory block level between the two groups (Table 1). The success rate of ONB was higher in group I compared to group $\mathrm{P}(96.1 \%$ vs. $84.0 \%, \mathrm{P}=0.046)$ and the frequency of needle attempts was also lower in group $\mathrm{I}$ than in group $\mathrm{P}(\mathrm{P}=0.01$ : Table 2). Mild obturator signs occurred during the operation in 3 of the 10 failed cases (2/8 vs. $1 / 2)$, but the procedures were completed without general anesthesia. None of the patients with successful ONB showed obturator signs during operation. There were no ONB-related complications such as hematoma, postoperative sensory or motor changes.

\section{Discussion}

We compared the success rate of an inguinal approach and a pubic approach for obturator block with spinal anesthesia for transurethral resection of bladder lateral wall masses.

The obturator nerve originates from the lumbar plexus of L2 to L4 and contains both motor and sensory nerve fivers. It runs close to the prostatic urethra, bladder neck and inferolateral bladder wall within the pelvic cavity $[10,11]$. When the bladder is distended with irrigation fluid during transurethral

Table 2. Characteristics of Obturator Nerve Block by Group

\begin{tabular}{lcc}
\hline \multicolumn{1}{c}{ Group } & Group P (n=50) & Group I (n=51) \\
\hline Success rate \% (n) & $84.0(42 / 50)$ & $96.1(49 / 51)^{*}$ \\
Distance of FA-ALM (cm) & $8.1 \pm 0.9$ & $8.9 \pm 1.6$ \\
Palpability of pubic tubercle & & \\
(well/fair/poor) & $22 / 22 / 6$ & $27 / 12 / 12$ \\
Needle depth (cm) & $3.3 \pm 0.6$ & $4.3 \pm 0.9^{*}$ \\
Puncture frequency (n) & $1.8 \pm 0.9$ & $1.3 \pm 0.6^{*}$ \\
Adductor contraction during & $2 / 8$ & $1 / 2$ \\
operation in failed cases (n) & &
\end{tabular}

Data represent the mean $\pm \mathrm{SD}, \%$, or number of patients. FA: femoral artery, ALM: inner margin of adductor longus muscle. *Significant at $\mathrm{P}<0.05$. 
procedure, the obturator nerve becomes very close to the lateral wall of the bladder and electrical currents can stimulate the obturator nerve accompanied by activation of adductor muscles of the thigh. Motor neurons carry A $\alpha$ fibers which are thicker in diameter. For an effective obturator block, the local anesthetic concentration must exceed that for pain and temperature sensations, which are carried by thin A $\delta$ and C fiber, by 2 -fold. Thus the concentration of lidocaine used must be greater than $1 \%$ for an effective motor block [12]. Lidocaine is commonly used since it has rapid onset and can last up to 40 minutes, making it suitable for blocking obturator signs at the usual dose of 10 to $20 \mathrm{ml}$ [13].

Although various imaging techniques have been used in an effort to increase the success rate of ONB [14-18], a blind approach using nerve stimulators is still a common technique. The success rate of ONB with the classical pubic method varies from $60.5 \%$ to $91.7 \%$ [6,7]. Even in the most experienced hands, this block can be missed. For the pubic approach, the pubic tubercle is the most definitive landmark. Sometimes the identification of the pubic tubercle is difficult in obese patients or patients with a blunt pubic bone. When identification of the tubercle is difficult, the needle may pass above the pubic ramus and may cause damage to the surrounding structures (bladder, rectum, spermatic cord). Furthermore, this approach is performed in a highly vascularized region [19]. Although no one showed ONB-related complications in our study, careful approach is mandatory with this technique to avoid the damage to surrounding structures and vessels. In comparison, the inguinal approach is performed at a distance from the pelvis and large vessels, thus this technique may minimize the risk of the aforementioned complications and allows compression in the case of hematoma [9]. Even though this inguinal approach has the limitation of reaching obturator branches contributing to hip joint innervation which occurs frequently before entry of the nerve into the thigh, it generally has little effect on the procedure during TURB [9].

In our study, we defined a successful block when any adductor muscle contraction occurred within three needle attempts and muscle contraction did not occur during the operation. The success rate of ONB was significantly higher with the inguinal approach than with the pubic approach $(96.1 \%$ vs. $84.0 \%, \mathrm{P}=0.046$ ). The safety and clinical applicability of ultrasound-guided ONB is frequently reported, although there is a study where the success rate with ultrasound-guided ONB was similar to that reported in studies using nerve stimulation [20]. However, ONB using nerve stimulation was the most used technique until ultrasound was commonly available in the clinical setting.

There are limitations to this study. First, this was a relatively small sample size. In our preliminary study, we expected the difference in means for success to be about $30 \%$. However, we found that the difference of success between the two approaches was $12.1 \%(\mathrm{P}=0.046)$. Thus, further study is needed to increase the reliability of this finding.

In conclusion, the inguinal approach for ONB seems to be technically easier as it offers certain anatomical advantages in comparison with the pubic approach, although both approaches can provide adequate blockade for the completion of the transurethral resection of lateral bladder wall tumors.

\section{Acknowledgements}

The authors are grateful to Dong-Su Jang, for his help with the figures.

\section{References}

1. Akata T, Murakami J, Yoshinaga A. Life-threatening haemorrhage following obturator artery injury during transurethral bladder surgery: a sequel of an unsuccessful obturator nerve block. Acta Anaesthesiol Scand 1999; 43: 784-8.

2. Shulman MS, Vellayappan U, Monaghan TG, Coukos WJ, Krenis LJ. Simultaneous bilateral obturator nerve stimulation during transurethral electrovaporization of the prostate. J Clin Anesth 1998; 10: 518-21.

3. Hobika JH, Clarke BG. Use of neuromuscular blocking drugs to counteract thigh-adductor spasm induced by electrical shocks of obturator nerve during transurethral resection of bladder tumors. J Urol 1961; 85: 295-6.

4. Lief PA, Narins L. Abolition of mass femoral muscular contractions during transurethral resection. J Mt Sinai Hosp N Y 1957; 24: 23-5.

5. Parks CR, Kennedy WF Jr. Obturator nerve block: a simplified approach. Anesthesiology 1967; 28: 775-8.

6. Macalou D, Trueck S, Meuret P, Heck M, Vial F, Ouologuem S, et al. Postoperative analgesia after total knee replacement: the effect of an obturator nerve block added to the femoral 3-in-1 nerve block. Anesth Analg 2004; 99: 251-4.

7. Kakinohana M, Taira Y, Saitoh T, Hasegawa A, Gakiya M, Sugahara K. Interadductor approach to obturator nerve block for transurethral resection procedure: comparison with traditional approach. J Anesth 2002; 16: 123-6.

8. Wassef MR. Interadductor approach to obturator nerve blockade for spastic conditions of adductor thigh muscles. Reg Anesth 1993; 18: $13-7$

9. Choquet O, Capdevila X, Bennourine K, Feugeas JL, BringuierBranchereau S, Manelli JC. A new inguinal approach for the obturator nerve block: anatomical and randomized clinical studies. Anesthesiology 2005; 103: 1238-45.

10. Brown DL. Atlas of Regional Anesthesia. Philadelphia, PA, WB Saunders. 1992, pp 103-8.

11. Berberoğlu M, Uz A, Ozmen MM, Bozkurt MC, Erkuran C, Taner S, et al. Corona mortis: an anatomic study in seven cadavers and an endoscopic study in 28 patients. Surg Endosc 2001; 15: 72-5.

12. Atanassoff PG, Weiss BM, Brull SJ. Lidocaine plasma levels 
following two techniques of obturator nerve block. J Clin Anesth 1996; 8: 535-9.

13. Fujita Y, Kimura K, Furukawa Y, Takaori M. Plasma concentrations of lidocaine after obturator nerve block combined with spinal anaesthesia in patients undergoing transurethral resection procedures. Br J Anaesth 1992; 68: 596-8.

14. Taboada M, Rodriguez J, ALvarez J, Cortés J, Gude F, Atanassoff PG. Sciatic nerve block via posterior Labat approach is more efficient than lateral popliteal approach using a double-injection technique: a prospective, randomized comparison. Anesthesiology 2004; 101: 138-42.

15. Viel EJ, Perennou D, Ripart J, Pélissier J, Eledjam JJ. Neurolytic blockade of the obturator nerve for intractable spasticity of adductor thigh muscles. Eur J Pain 2002; 6: 97-104.

16. Heywang-Köbrunner SH, Amaya B, Okoniewski M, Pickuth D,
Spielmann RP. CT-guided obturator nerve block for diagnosis and treatment of painful conditions of the hip. Eur Radiol 2001; 11: 1047-53.

17. Soong J, Schafhalter-Zoppoth I, Gray AT. Sonographic imaging of the obturator nerve for regional block. Reg Anesth Pain Med 2007; 32: 146-51.

18. Akkaya T, Ozturk E, Comert A, Ates Y, Gumus H, Ozturk H, et al. Ultrasound-guided obturator nerve block: a sonoanatomic study of a new methodologic approach. Anesth Analg 2009; 108: 1037-41.

19. Miller RD. Miller's anesthesia. 6th ed. Philadelphia, Churchill Livingstone. 2005, pp 1695-704.

20. Sinha SK, Abrams JH, Houle TT, Weller RS. Ultrasound-guided obturator nerve block: an interfascial injection approach without nerve stimulation. Reg Anesth Pain Med 2009; 34: 261-4. 